\title{
REMOVAL OF TERASIL BLUE DYE FROM SYNTHETIC WASTEWATER USING LOW COST AGRO-BASED ADSORBENTS
}

\author{
Hatem Asal Gzar, \\ Assistant Prof. Dr./Civil Eng. Department/ College of Engineering/ Wasit University. \\ E mail: hatam_asal@yahoo.com \\ Noor Qassim Sabri, \\ Civil Eng. Department/ College of Engineering / Wasit University. \\ E mail:_engnoorqassim@yahoo.com
}

\begin{abstract}
Natural materials that are readily available in large amounts in nature and easily accessible may be used as low cost additives. The aim of this study is to measure the susceptibility of these locally available materials, conocarpus plant, to improve the quality of wastewater discharged from textile industry.

In addition to conocarpus plant, carbonized conocarpus and activated carbon were used as adsorbents in order to make a comparison, and to test which one of the three types give the best efficiency for removing dye. The ability of adsorbents to adsorb dye was studied using batch system; studied parameters were effect of $\mathrm{pH}$, dose of adsorbents, time, and agitation speed. The experimental results showed that the maximum removal efficiency of conocarpus was found to be $87.5 \%$ at $50 \mathrm{rpm}$ mixing speed, $\mathrm{pH}$ value 3 , mixing time $120 \mathrm{~min}$ and the dose of adsorbent was $0.25 \mathrm{~g}$. The maximum removal efficiency for carbonized conocarpus was up to $98.7 \%$ at $150 \mathrm{rpm}$ mixing speed, $\mathrm{pH}$ value 3 , mixing time was equal to 7 hours and the dose of sorbent was $1.25 \mathrm{~g}$. For activated carbon the maximum removal efficiency was found to be $99 \%$ at mixing speed of $200 \mathrm{rpm}$, $\mathrm{pH}$ value 3 or 11, mixing time was equal to 7 hours and the dose of the sorbent was 1.25 g. The above removal efficiencies were obtained at temperature $20^{\circ} \mathrm{C}$.
\end{abstract}

Keywords: Terasil blue dye, Wastewater, Adsorption, Low cost adsorbent, Batch study.

\section{INTRODUCTION}

The lack of water on the surface of the earth has become one of the biggest problems faced by humans. The population is growing rapidly and thus increasing the need for industrial processes and the consumption of the goods produced by the industries, thus increasing water consumption and increasing pollution. More than half the water is used to meet the needs of the humans and the second half in agriculture and industrial processes (Tang and Chen, 2002). 


\section{AL-QADISIYAH JOURNAL FOR ENGINEERING SCIENCES}

Vol. 11, No. 2

ISSN: $1998-4456$

In addition to water shortages, industrial processes, through the discharge of waste water in the water bodies, lead to serious environmental problems. Although the treatment of contaminated water is the responsibility of the environmental protection legislation, most industrial companies in the world do not have processing units, and they are not sufficiently efficient. All these facts are the pressure of industrialists to consider the development and reuse of contaminated water (Gökşen et al., 2005).

The textile industry is one of the oldest and largest industries which release the contaminants to the environment. The subject of pollutants has been studied by many researchers for many years because it poses a significant risk to the environment due to its chemical nature. The spinning and weaving industries are made up of a large number of steps that are produced by converting natural elements such as cotton, wool, and silk, converting them into fibers and then converting them into cloth through textile and knitting processes and finally finishing them with dyeing, printing and finishing. These steps include processing textiles in chemical baths and often require washing and rinsing. Thus, these sequential steps lead to large consumption of water and the production of contaminants in large quantities. Textile dyeing is the most important process in terms of pollutant generation and large environmental impacts (Gökşen et al., 2005)

The polluted water produced by the fabric processes is characterized by large quantities of dye produced by pigments; salts, derived from additives used to stabilize dyes, detergents, complexity factors, fiber residue, high temperature and $\mathrm{pH}$ fluctuation. The textile industry, including the textile and dyeing industry, typically produces 200-500 liters of contaminated water per $\mathrm{kg}$ of the final product (Marcucci et al., 2001).

Many chemical, physical, and biological processes have been used such as image oxidation and adsorption processes; to remove the chemical dyes used in the dyeing process. At all times, the adsorption process is used to collect chemical dyes on a solid matrix before the biological and chemical treatments (Ozmihci and Kargi, 2006; Aydın et al., 2007).

The process of selecting a method of treatment depends on the nature, type, concentration and other components of the liquid contaminants, cost and removal efficiency. Common treatment processes such as rainfall and ion exchange are either costly or ineffective in removing pollutants from water. There is a great need for new, cost-effective and efficient ways of treating effluents (Ghodbane et al., 2008; Figueira et al., 2000).

The choice of adsorbent type is an important point in the development of the absorption process. Several materials can be used to remove industrial dyes. One of the materials used as a adsorbent is activated carbon powder although it has a high price but it is the most effective material used to remove organic compounds because of large area (1000 m2 G-1) and its high ability to absorb (Mohan and Karthikeyan, 1997; Kestioglu and Yalili, 2006; Akdemir and Ozer, 2013).

Therefore, it would be correct to use alternative and low cost materials such as agricultural products to be used as an adsorbent; and that these agricultural products are not used only to remove metals but to remove dyes and all solid waste. (Satyawali and Balakrishnan, 2008; Febrianto et al., 2009; Sousa et al., 2009).

Many kinds of agricultural crops have been studied to dispose of dye from sewage, like mud produced by the sugar industry (Magdy and Deifullah, 1998), rice husk (Mckay et al., 1986), peel of orange ( Namasivayam et al., 1996) and other agricultural crops like wood ( Ho and Mackay, 1998), cassava peels and Kenaf (Hussein, 2016).

In this study a new, environment friendly, non-conventional, cost-effective, and locally available conocarpus was investigated for the adsorption of terasil blue dye from synthetic wastewater. The effects of different parameters such as $\mathrm{pH}$, dose of the adsorption, contact time, and agitation speed were studied. 


\section{AL-QADISIYAH JOURNAL FOR ENGINEERING SCIENCES}

Vol. 11, No. 2

ISSN: $1998-4456$

\section{EXPERIMENTAL PROCEDURE AND METHODS}

\subsection{PREPARATION OF TERASIL BLUE}

The solution was prepared by dissolving (20) $\mathrm{mg}$ of terasil blue dye in $1000 \mathrm{ml}$ of tap water. The dye components (Table 1) were examined using Eds device (Type X - act, USA). The measurements were conducted at the Central service laboratory - College of Education Ibn Al Haitham , Baghdad.

Table 1. the components in terasil blue dye

\begin{tabular}{|l|l|l|}
\hline Element & Weight\% & Atomic\% \\
\hline $\mathrm{C}$ & 37.45 & 50.29 \\
\hline $\mathrm{O}$ & 35.52 & 35.81 \\
\hline $\mathrm{Na}$ & 9.89 & 6.94 \\
\hline $\mathrm{S}$ & 8.52 & 4.29 \\
\hline $\mathrm{Cl}$ & 3.72 & 1.69 \\
\hline $\mathrm{Br}$ & 4.90 & 0.99 \\
\hline Totals & 100.00 & 100.00 \\
\hline
\end{tabular}

\subsection{PREPARATION OF THE ADSORBENTS}

Three adsorbent materals are prepared for adsorption study.

\subsubsection{Preparation of conocarpus adsorbent}

Conocarpus leaves was taken from the campus of Wasit University to be used in this study. The previous studies (Hussein et al 2016) was adopted as a working method for preparation of conocarpus in the following steps: cutting the plant's leaves, and washing them three times by using distilled water to get rid of any dust. After finishing washing, they were dried in the oven at $110^{\circ} \mathrm{C}$ for 3 hours; then grinded in a mill to a small volume of less than 500 microns. The last step of the preparation process is sieving through (150 300) $\mu \mathrm{m}$. Figure 1 shows the Preparation of conocarpus adsorbent.

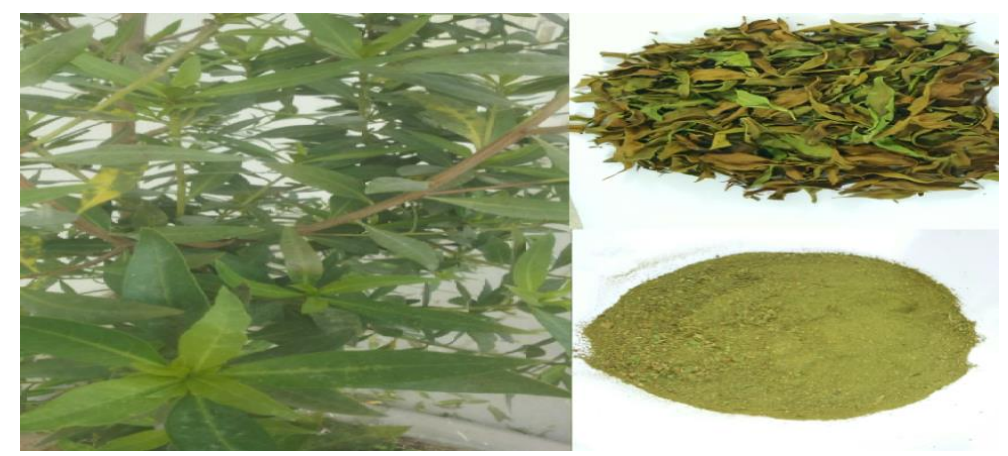

Figure 1. Preparation of conocarpus adsorbent.

\subsubsection{Preparation of carbonized conocarpus}

The previous studies (Ramadan et al. 2005) was adopted as a working method for carbonization of conocarpus plants in the following steps:

1. Cutting the plant into small pieces.

2. Washing it three times with distilled water to to clean it.

3. Dry it with a $110^{\circ} \mathrm{C}$ for three hours and repeat the drying step for anther quantities until the required quantity is obtained. 


\section{AL-QADISIYAH JOURNAL FOR ENGINEERING SCIENCES}

Vol. 11 , No. 2

ISSN: 1998-4456

4. The dried plant is grinded into small granules using grinder.

5. 1: 0.5 of the conocarpus and sodium hydroxide are mixed well.

6. Put the mixture in oven at temperature $300^{\circ} \mathrm{C}$ for half an hour with continuous flipping.total time for carbonization process was two hours.

7. Wash the product in the filtration device twice with distilled water and then washed with hydrochloric acid at a concentration of $10 \%$ once to remove the effect of base solution then wash it with water once to remove acidic excitation.

8. The product is then dried in oven at $110^{\circ} \mathrm{C}$ for three hours, then grinded into small granules.

9. Sieving the product through $(150-300 \mu \mathrm{m})$.

\subsection{ACTIVATED CARBON}

The powder activated carbon (PAC) (German origin) was used as adsorbent if the experiments (figure 2), its composition are shown in Table 2.

Table 2. Specifications of activated carbon.

\begin{tabular}{|l|l|}
\hline Specification & Value \\
\hline $\mathrm{MW}$ & $12.01 \mathrm{~g} / \mathrm{mol}$ \\
\hline Soluble in water & $<0.2 \%$ \\
\hline Soluble in $\mathrm{HCL}$ & $<1 \%$ \\
\hline Soluble in $\mathrm{C}_{2} \mathrm{H}_{5} \mathrm{OH}$ & $<0.2 \%$ \\
\hline Chloride $\mathrm{Cl}$ & $<0.001 \%$ \\
\hline Cooper $\mathrm{Cu}$ & $<0.05 \%$ \\
\hline Iron $\mathrm{Fe}$ & $<0.002 \%$ \\
\hline Lead $\mathrm{Pb}$ & $<0.001 \%$ \\
\hline
\end{tabular}

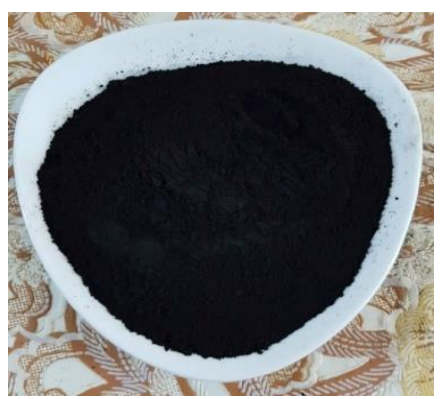

Figure 2. Activated carbon

\subsection{BATCH EQUILIBRIUM STUDY}

$100 \mathrm{ml}$ of $20 \mathrm{mg} / \mathrm{L}$ terasil blue was poured in flasks of $250 \mathrm{ml}$ size, $0.5 \mathrm{~g}$ of adsorbents of activated carbon , conocarpus, and carbonized conocarpus is placed in flasks. $\mathrm{pH}$ of the mixture was determined using $\mathrm{pH}$ meter. The flasks then placed in orbital shaker (Type TS-2,Turki) for two hours. Centrifugal separator ( Type 80-1 Electric Centrifugal ,Taiwan) was used for 15 minutes then filtration process was achieved using filtration device. The final step was analyzing the amount of dye removal using spectrophotometer (Type ufb1105014,German) with a maximum wavelength of $663 \mu \mathrm{m}$ (Hussein et al 2016). The effect of various parameters, adsorbent dose, $\mathrm{pH}$, contact time and agitation speed were studied. The adsorbed amount $\mathrm{q}_{\mathrm{e}}$ was calculated using the following equation: 


$$
\mathrm{q}_{\mathrm{e}}=\frac{\mathrm{V}_{\mathrm{L}}\left(\mathrm{C}_{\mathrm{o}}-\mathrm{C}_{\mathrm{e}}\right)}{\mathrm{W}_{\mathrm{o}}}
$$

Where: $q_{e}$ is the equilibrium uptake $(\mathrm{mg} / \mathrm{g}), V_{L}$ is the volume of the solution(I), $C_{o}$ is the initial concentration $(\mathrm{mg} / \mathrm{l}), \mathrm{C}_{\mathrm{e}}$ is the equilibrium concentration $(\mathrm{mg} / \mathrm{l}), \mathrm{W}_{\mathrm{o}}$ is the mass of biosorbent.

The biosorption removal efficiency was calculated by the difference of the initial and equilibrium concentration of terasil blue dye according to the following equation:

$$
\text { Removal\% }=\frac{\left(\mathrm{C}_{\mathrm{o}}-\mathrm{C}_{\mathrm{e}}\right)}{\mathrm{C}_{\mathrm{o}}} \times 100
$$

\section{RESULTS AND DISCUSSION}

\subsection{CALIBRATION CURVE}

Solution of terasil dye (1000 $\mathrm{mg} / \mathrm{L})$ was used to find the calibration curve. Different dilute concentrations were prepared for calibration curve as shown Figure 3.

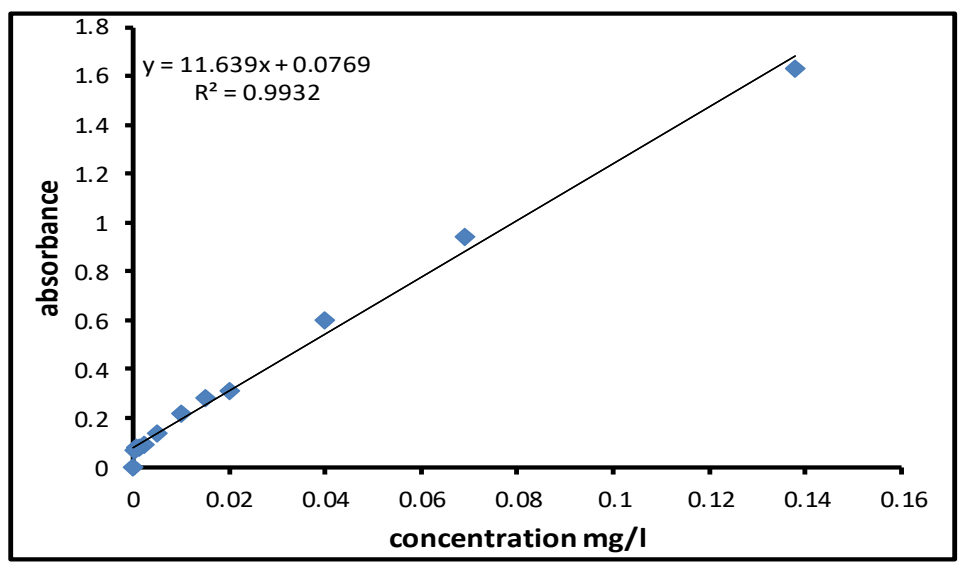

Figure 3. Calibration curve of terasil blue solutions 


\section{AL-QADISIYAH JOURNAL FOR ENGINEERING SCIENCES}

Vol. 11, No. 2

ISSN: 1998-4456

\subsection{EFFECT OF CONTACT TIME ON REMOVING OF TERASIL BLUE}

Using activated carbon, carbonized conocarpus and conocarpus as absorbent materials, the percentage of removal of terasil blue was obtained at different contact times, keeping other parameters constant such as $\mathrm{pH}$ solution, sorption dose and shaker rotary velocity.

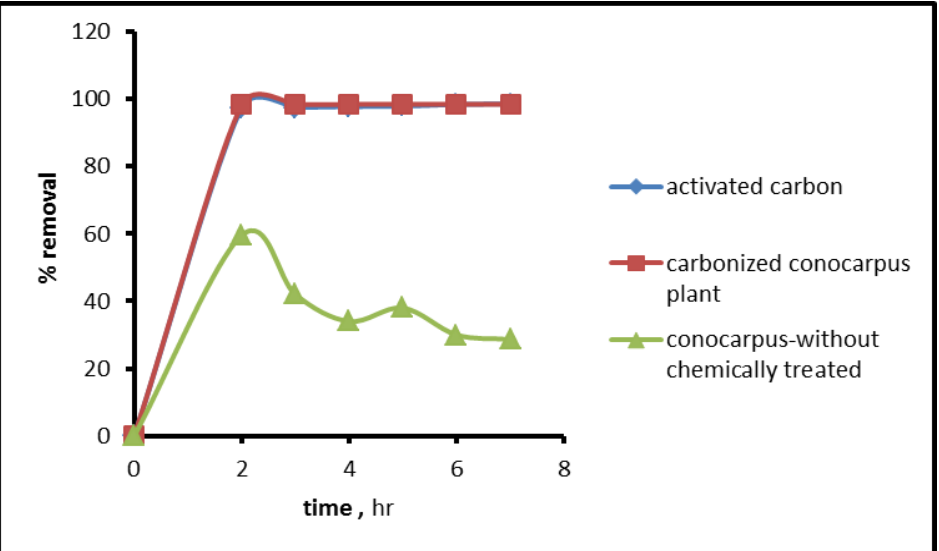

Figure 4. Percentage of terasil blue removal onto activated carbon, conocarpus plant and carbonized conocarpus at different contacting time, keeping other parameters constant such as $\mathrm{pH}$ solution, sorption dose, shaker rotary velocity and temperature $20^{\circ} \mathrm{C}$.

Figure 4 shows when activated carbon was used and carbonized conocarpus that dye adsorption increase with increasing time and remains constant after reaching equilibrium. This is due to a larger area of absorbent material at the beginning of the adsorption process. As surface adsorption sites are exhausted, the absorption rate controls the rate at which adsorption from external sites is transferred to the interior of the sorbent molecules. The upper percentage was achieved to remove the dye after about 7 hours of shaking time. The result is consistent with those obtained by Sumanjit et al. (2008).

When conocarpus is used, it is apparent that the removal of dye decreases with increasing time, because the plant did not undergo carbonation processes, but only drying, so it kept green color , the more time increases the ability to give the color. The best time for adsorption is at the second hour.

From figure 4 it is shown that activated carbon and carbonized conocarpus were more effective in the process of adsorption where the efficiency of removal $98.56 \%$ and $98.53 \%$ respectively followed by the dried conocarpus plant $59.57 \%$.

\subsection{EFFECT OF ADSORBENT DOSAGE ON REMOVAL OF TERASIL BLUE}

The influence of adsorbent dosage on removal efficiency of terasil blue dye has been investigated. Five amounts of each adsorbent $(0.25,0.5,0.75,1$, and $1.25 \mathrm{~g})$ were used; at the following conditions: $20 \mathrm{mg} / \mathrm{l}$ concentration of terasil blue solution, rotating speed $150 \mathrm{rpm}$, and temperature $25^{\circ} \mathrm{C}$.

Figure 5 shows the relationship between the ratio of removal efficiency and different dose of sorbent, of activated carbon, carbonized conocarpus and conocarpus.

When the activated carbon and carbonized conocarpus was used, it appears that the efficiency of removal of the terasil dye increases with increasing dosage of the absorbent materials because of the availability of more adsorption sites and increase in the surfaces area of adsorbent, the result is consistent with those obtained by Selvaraj et al. (2003). 


\section{AL-QADISIYAH JOURNAL FOR ENGINEERING SCIENCES}

Vol. 11 , No. 2

ISSN: $1998-4456$

When conocarpus is used, the efficiency of the dye removal decreases with the increase of mass of sorbents, because the plant was used without carbonization and it is added a green dye to the solution, so the greater the dose the greater the ability to give color and reduce the process of adsorption.

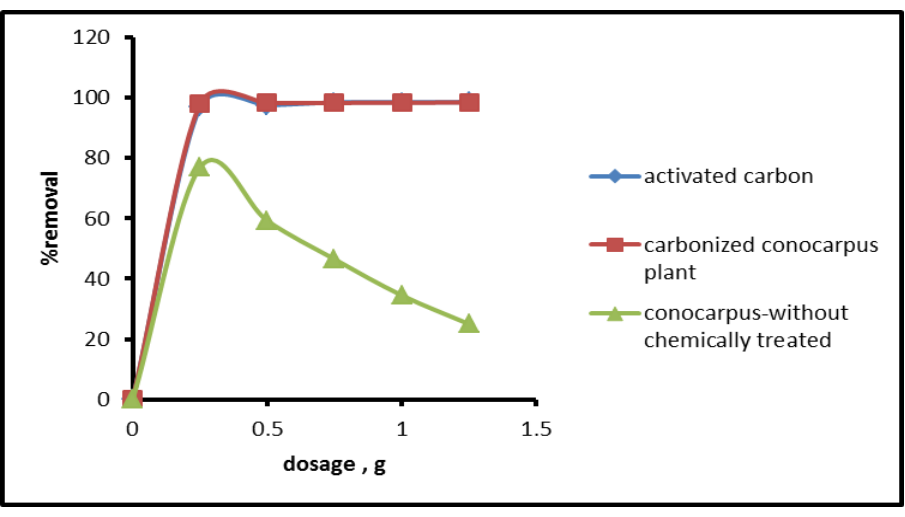

Figure 5. Percentage of terasil blue removal onto activated carbon, carbonized conocarpus and conocarpus , at different dosage, keeping other parameters constant such as $\mathrm{pH}$ solution, contact time, shaker rotary velocity and temperature $20^{\circ} \mathrm{C}$.

From figure 5 which represents the relationship between the efficiency of removal and adsorbent dosage, it is shown that activated carbon and carbonized conocarpus were more effective in the process of adsorption where the efficiency of removal $98.63 \%$ and $98.48 \%$, respectively at adsorbent dosage $1.25 \mathrm{~g}$ while the removal efficiency of conocarpus was 76.95 at dosage $0.25 \mathrm{~g}$.

\subsection{EFFECT OF PH ON THE ADSORPTION OF TERASIL}

$\mathrm{pH}$ have a significant effect in the adsorption process.pH of solution is effecting the surface charge of the adsorbent and the influences structural stability of terasil blue dye. The effect of $\mathrm{pH}$ solution has been study in the adsorption on terasil blue dye and the range was $(\mathrm{pH} 3-11)$. Figure 6 represents the effect of $\mathrm{pH}$ value on each adsorbent of terasil blue dye. The result is consistent with those obtained by Woolard et al. (2002).

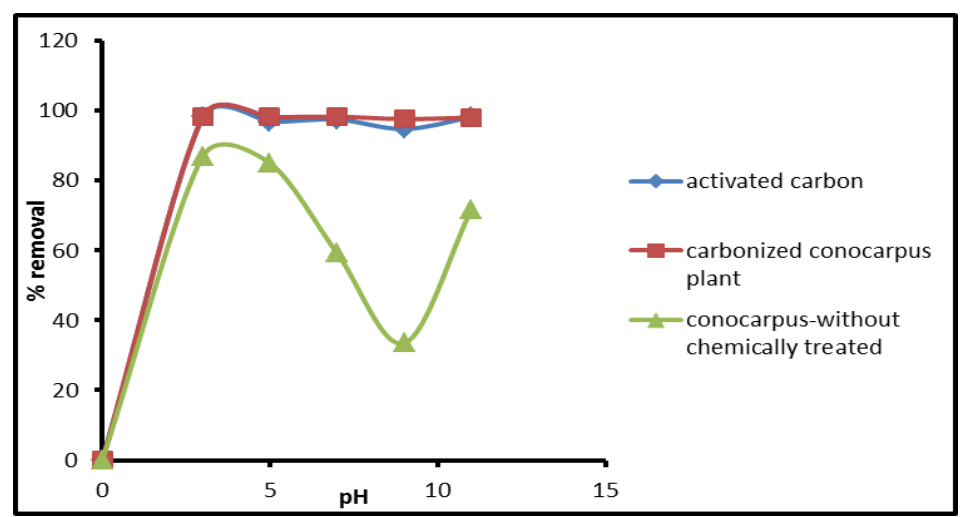

Figure 6. Percentage of terasil blue removal onto activated carbon, carbonized conocarpus plant and conocarpus plant, at different $\mathrm{pH}$ values, keeping other parameters constant such as contact time, sorption dose, shaker rotary velocity and temperature $20^{\circ} \mathrm{C}$. 


\section{AL-QADISIYAH JOURNAL FOR ENGINEERING SCIENCES}

Vol. 11, No. 2

ISSN: $1998-4456$

The optimum solution $\mathrm{pH}$ values for activated carbon were found to be 3 and 11, the removal efficiency was $98.18 \%$ at the two values of $\mathrm{pH}$. The maximum adsorption of terasil blue onto carbonized conocarpus was $98.43 \%$ followed by conocarpus $87 \%$ at $\mathrm{pH} 3$.

\subsection{Effect of Agitation Speed on the a dsorption of terasil blue}

From figure 7 using the three sorbents (activated carbon, carbonized conocarpus plant, conocarpus), which represents the relationship between the efficiency of removal and agitation speed, keeping other parameters constant such as $\mathrm{pH}$ solution, sorption dose and contact time, it is shown that activated carbon, is more efficiency of removal $98.33 \%$ at $200 \mathrm{rpm}$. Followed by carbonized conocarpus plant, where the maximum efficiency of removal $98.31 \%$ at $150 \mathrm{rpm}$, and for the dried conocarpus plant where the maximum efficiently removed $63 \%$ at $50 \mathrm{rpm}$.

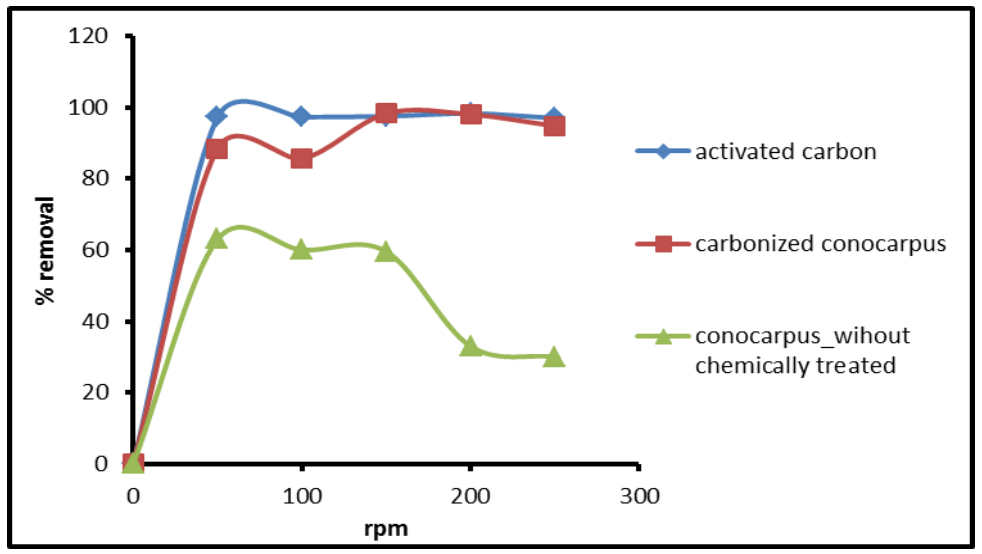

Figure 7. Effect of agitation speed in the adsorption of terasil blue onto activated carbon , carbonized conocarpus plant and conocarpus plant. at different agitation speed, keeping other parameters constant such as contact time, $\mathrm{pH}$ solution, sorption dose, and temperature $20^{\circ} \mathrm{C}$.

The speed of vibration affects the physicochemical interaction between the sorbent molecules and the terasil blue dye in the solution. The reduction in the removal efficiency after the speed of $200 \mathrm{rpm}$ is due to the accumulation of part of the sorbent (activated carbon, carbonized conocarpus plant and conocarpus) on the inner surface of the flask neck during the operation of the device which reduces absorption of the dye. Therefore $200 \mathrm{rpm}$ considered the optimum agitation speed for the adsorption process. These results are similar to those found by pehlivan and Altun., (2008).

In the case of ideal conditions for all effects and for all sorbents, the removal efficiency are as follows: the removal efficiency of conocarpus was found to be $87.5 \%$ at $50 \mathrm{rpm}$ mixing speed, $\mathrm{pH}$ value 3 , mixing time $120 \mathrm{~min}$ and the dose of adsorbent was $0.25 \mathrm{~g}$. The removal efficiency for carbonized conocarpus was up to $98.7 \%$ at $150 \mathrm{rpm}$ mixing speed, $\mathrm{pH}$ value 3 , mixing time was equal to 7 hours and the dose of sorbent was $1.25 \mathrm{~g}$. For activated carbon the removal efficiency was found to be $99 \%$ at mixing speed of $200 \mathrm{rpm}, \mathrm{pH}$ value 3 or 11 , mixing time was equal to 7 hours and the dose of the sorbent was $1.25 \mathrm{~g}$. The above removal efficiencies were obtained at temperature $20^{\circ} \mathrm{C}$. 


\section{AL-QADISIYAH JOURNAL FOR ENGINEERING SCIENCES}

Vol. 11, No. 2

ISSN: $1998-4456$

\section{CONCLUSION}

1. According to the results, it was found that using higher dosage of the sorbent, activated carbon and carbonized conocarpus plant ; led to greater efficiency of the removal of terasil blue dye. In case of using conocarpus, less efficiency of removal was obtained with increasing the dose of absorbent.

2. It has been shown that $\mathrm{pH} 3$ is the optimum value for the best adsorption process.

3. A higher adsorption efficiency was obtained when more contact time between the adsorbent, activated carbon and carbonized conocarpus plant, and terasil dye. In case of using conocarpus as adsorbent, the increase in time lead to less efficiency of removal.

4. it was found that $200 \mathrm{rpm}$ is the optimum speed for the adsorption process when was used activated carbon, 150 rpm when carbonized conocarpus plant use ,and 50 rpm when conocarpus were used.

\section{REFRENCES}

1. Akdemir EO and Ozer A (2013) Pretreatment of Cheese Whey Effluent Using a Microfiltration Process: A Statistical Design Approach. Ekoloji 22(88): 21-27.

2. Aydin S, Güneysu S and Arayici S (2007) Investigation of using adsorbents obtained from sewage sludge with pyrolysis for removal of cod and dye from textile industry wastewater. Ekoloji 16(64): 4348.

3. Figueira, M. M., Volesky, B., Ciminelli, V. S. T. and Roddick. F. A. (2000) Biosorption of metals in brown seaweed biomass, Water Research, 34, 1, 196-204.

4. Febrianto, J., Kosasih, A.N., Sunarso, J., Ju, Y., Indraswati, N. and Ismadji, S., (2009) Equilibrium and kinetic studies in adsorption of heavy metals using biosorbent: A summary of recent studies, Journal of Hazardous Materials, 162, 616-645.

5. Ghodbane, I., Nouri, L., Hamdaoui, O. and Chiha M., (2008) Kinetic and equilibrium study for the sorption of cadmium (II) ions from aqueous phase by eucalyptus bark, Journal of Hazardous Materials, 152,148-158.

6. Hussein M (2016) Removal of Methylene Blue Dye from Synthetic Wastewater Using Low Cost AgroBasedAdsorbents MSc. thesis, College of Engineering, University Putra Malaysia.

7. Ho, YS. And McKay, G., (1998) Kinetic models for the sorption of dye from aqueous solution by wood. Process Safety and Environmental Protecttion 76B: 183-191.

8. Korbahti B K (2007). Response surface optimization of electrochemical treatment of textile dye wastewater. Journal of Hazardous Materials 145: 277-286.

9. Kestioglu K and Yalili M (2006). Treatability of textile industry wastewater with high cod content by chemicalprecipitation and adsorption. Ekoloji 15(59): 27-31.

10. Levent, E., Gökşen, D., Ozyürek, A. R., Darcan, S., \& Coker, M., (2005), Usefulness of the myocardial performance index (MPI) for assessing ventricular function in obese pediatric patients. Turk J Pediatr, (47(1), 34-8).

11. Marcucci, M. C., Ferreres, F., Garcıa-Viguera, C., Bankova, V. S., De Castro, S. L., Dantas, A. P., and Paulino, N., (2001). Phenolic compounds from Brazilian propolis with pharmacological activities. Journal of ethno pharmacology, (74(2), 105-112) . 


\section{AL-QADISIYAH JOURNAL FOR ENGINEERING SCIENCES}

Vol. 11, No. 2

ISSN: $1998-4456$

12. Magdy YH and Daifullah AAM (1998) Adsorption of a basic dye from aqueous solutions onto sugarindustrymud in two modes of operations. Waste Managment 18: 219-226.

13. McKay G, Ramprasad G and Pratapamowli $P$ (1986) Equilibrium studies for the adsorption of dyestuffs from aqueous solution by low-cost materials. Water Air Soil Pollution 29: 273-283

14. Mohan SV and Karthikeyan J (1997). Removal of lignin and tannin colour from aqueous solution by adsorption onto activated charcoal. Environmental Pollution 97: 183-187.

15. Namasivayam C, Muniasamy N, Gayatri K, Rani M and Ranganathan K (1996) Removal of dyes from aqueous solutions by cellulosic waste orange peel. Bioresource Technology 57: 37-43.

16. Ozmihci $S$ and Kargi $F$ (2006) Utilization of powdered waste sludge (PWS) for removal of textile dyestuffs from wastewater by adsorption. Journal of Environmental Management 81(3): 307-314

17. Pehlivan, E. and Altun, T., (2008) Biosorption of chromium(VI) ion from aqueous solutions using walnut, hazelnut and almond shell, Journal of Hazardous Materials, 155,1-2, 378-384.

18. Ramadan A, Ghazal R and Jarges K (2005) Preparation of activated carbon from cocusTree residues using modified carbonate and chemical thermal activating, Qatar Journal of Chemistry 18,161-169

19. Sumanjit L., Tejinder, P., Singh, W. and Ishu, K., (2008) "Removal of Rhodamine-B by adsorption on walnut shell charcoal”, Journal of surface Science Technology,24,3-4,179-193.

20. Satyawali, Y. and Balakrishnan, M., (2008) Wastewater treatment in molasses-based alcohol distilleries for COD and color removal, A review, Journal of Environmental Management, 86, 481-497.

21. Sousa, F.W., Oliveira, A.G., Vicente, O.S., NetoFechine, P.B.A., Keukeleire, D., Cavalcante, R.M., Oliveira, I.R.N., SousaJames, M. and Nascimento, R.F., (2009) Evaluation of a low-cost adsorbent for removal of toxic metal ions from wastewater of electroplating factory, Journal of Environmental Management, 90, 3340-3344.

22. Tang, S. and Chen, L., (2002). Density-dependent birth rate, birth pulses andtheir population dynamic consequences. Journal of Mathematical Biology,(44(2), 185-199).

23. Woolard C, Strong J, Erasmus C (2002) Evaluation of the use of modified coal ash as a potential sorbent for organic waste streams. Applied Geochemistry 17: 1159-1164. 